\title{
Involvement of neuropeptide $Y$ in glucose sensing in the dorsal hypothalamus of streptozotocin diabetic rats - in vitro and in vivo studies of transmitter release
}

\author{
M. Gozali, J. M. Pavia, M. J. Morris \\ Neuroendocrine Laboratory, Department of Pharmacology, University of Melbourne, Victoria, Australia
}

\begin{abstract}
Aims. Within the brain, subgroups of neurons respond differently to altered glucose concentrations. Identification of neuropeptide $\mathrm{Y}$ in hypothalamic neurons that sense glucose suggests a role for neuropeptide $\mathrm{Y}$ in glucose sensing. Using in vitro and in vivo techniques to monitor transmitter release, we investigated whether lowering glucose concentration affects the release of neuropeptide $\mathrm{Y}$ from the brain, and whether this process is altered in Type I (insulin-dependent) diabetes mellitus.

Methods. Male Sprague-Dawley rats were treated with $48 \mathrm{mg} / \mathrm{kg}$ streptozotocin or vehicle intravenously. The effect of reduced glucose on endogenous neuropeptide $\mathrm{Y}$ overflow from slices of hypothalamus and medulla incubated in Krebs solution was examined 4 weeks later. The hypothalamus was separated into a dorsal region containing the paraventricular nucleus and a ventral region containing the arcuate nucleus.

Results. Streptozotocin-induced diabetes increased basal neuropeptide Y overflow in the dorsal and ven-
\end{abstract}

tral hypothalamus $(p<0.05)$ but not the medulla. In vitro neuropeptide Y overflow was reduced by low glucose in the dorsal hypothalamus in diabetic, but not in control rats. No effect of reduced glucose was observed in the ventral hypothalamus or medulla. In vivo push-pull studies in the paraventricular nucleus also showed greater neuropeptide $\mathrm{Y}$ overflow in diabetic rats relative to control rats $(p<0.05)$. Insulininduced hypoglycaemia induced a decrease in neuropeptide $\mathrm{Y}$ overflow in diabetic rats, while an increase was observed in control rats $(p<0.05)$.

Conclusion. These region-specific effects of low glucose on neuropeptide $\mathrm{Y}$ overflow in diabetic rats support a part for neuropeptide $\mathrm{Y}$ in altered glucose sensing in Type I diabetes. [Diabetologia (2002) 45:1332-1339]

Keywords Brain, glucose sensing, hypoglycaemia, hypothalamus, medulla, neuropeptide Y, neurotransmitter release, push-pull, streptozotocin, Type I diabetes mellitus.
Received: 11 February 2002 / Revised: 2 May 2002

Published online: 12 July 2002

C) Springer-Verlag 2002

Corresponding author: Dr. M. J. Morris, Department of Pharmacology, University of Melbourne, Victoria, 3010 Australia, E-mail: mjmorris@ unimelb.edu.au

Abbreviations: ARC, Arcuate nucleus; CNS, central nervous system; DMN, dorsomedial nucleus; GR, glucose responsive; GS, glucose sensitive; LH, lateral hypothalamus; LSD, least significance difference; NPY, neuropeptide Y; NTS, nucleus tractus solitarius; PVN, paraventricular nucleus; VMN, ventromedial nucleus; WAT, white adipose tissue
Long-term maintenance of tight glycaemic control through multiple daily injections or an insulin pump has been shown to be protective against the onset and progression of the long-term complications of Type I (insulin-dependent) diabetes mellitus $[1,2]$. However, recurrent hypoglycaemia becomes an inevitable problem in intensive insulin treatment, contributing to diabetes morbidity and mortality [3].

Acute hypoglycaemia causes cognitive dysfunction, without impairing the function of the peripheral nervous system [4], while untreated hypoglycaemia can progressively lead to coma, convulsions and eventually death. The response to insulin-induced hypo- 
glycaemia involves increased plasma concentrations of the counter-regulatory hormones, namely glucagon, adrenaline, cortisol and growth hormones [5]. Hypoglycaemic patients generally have neurogenic and neuroglycopenic symptoms [6]. These symptoms tend to occur at a higher plasma glucose concentration in chronically hyperglycaemic Type I diabetic patients [7]. However, during intensive insulin therapy, specifically after recurrent episodes of hypoglycaemia, a glycaemic threshold shift occurs, and lower plasma glucose concentrations are required to activate the same defence mechanisms $[6,8]$. This can result in a clinical syndrome known as hypoglycaemia unawareness, with a loss of warning symptoms. Hypoglycaemia unawareness has been proposed to produce a 25 -fold increase in the frequency of severe hypoglycaemia in Type I diabetic patients [9, 10], resulting in initiation of a vicious cycle of hypoglycaemia.

Although the distinct mechanisms underlying hypoglycaemia unawareness are still not clear, several hypotheses have been suggested [11, 12]. Various mechanisms could contribute to the loss of warning symptoms, and brain glucose sensing is likely to play a major role in regulating the simultaneous responses to hypoglycaemia and the activation of counter-regulatory responses. Glucose sensing in the central nervous system (CNS) has been associated with the glucose sensing neurons [13]. Clear evidence of abnormalities in central glucose sensing and transport have been shown in Type I diabetes, involving a resetting of the normal homeostatic mechanisms [14], and more recently in diet-induced obesity [15].

Select groups of neurons in the brain respond to moderate changes in blood glucose by altering their firing rate. Glucose-sensitive (GS) neurons decrease their firing rate upon increased glucose concentrations, while glucose-responsive (GR) neurons are those that increase their firing in response to increased glucose concentrations. Since the proposal of glucose sensing neurons in the hypothalamus [16], many studies have investigated this question. Effects of systemic glucose on neurons of the lateral hypothalamus ( $\mathrm{LH})$, ventromedial nucleus (VMN), paraventricular nucleus (PVN) and arcuate nucleus (ARC) of the hypothalamus, as well as the nucleus tractus solitarius (NTS) of the brainstem have been reported in several mammalian species, including the cat, rat and mouse $[17,18$, $19,20,21]$. However, the characteristics of these neurons remain largely unknown. Several candidate transmitters are implicated in central glucose sensing, including some amino acids, catecholamines and neuropeptide Y (NPY) [19, 22].

Neuropeptide $Y$ is a 36 amino acid peptide member of the pancreatic polypeptide family found at high concentrations in the hypothalamus, predominantly synthesised in the cell bodies of neurons in the ARC that project to the dorsomedial nuclei (DMN) and PVN [23]. The NPY-containing neurons in the ARC have been implicated in feeding [24] and glucosesensing [19]. Furthermore, NPY mRNA and NPYoverflow from several hypothalamic sites was shown to be increased in streptozotocin-induced diabetic rats compared to control rats $[25,26]$. Taken together, these findings suggest a role for NPY in glucose sensing and Type I diabetes.

Although many studies have investigated how changing glucose concentrations affect neuronal activity in the brain, much remains to be discovered about the role of the neurotransmitters involved in glucose sensing. We investigated the role of NPY in central glucose sensing in the rat both in vitro and in vivo. Specifically, we aimed to examine whether the release of NPY in areas incorporating different types of glucose sensing neurons, within the dorsal and ventral hypothalamus, or medulla oblongata, is regulated by reduced glucose concentrations, and to compare this response in control rats and diabetic rats.

\section{Materials and methods}

Animals. Male Sprague-Dawley rats were habituated to a 12:12 h light:dark cycle under controlled temperature $\left(20 \pm 2^{\circ} \mathrm{C}\right)$, with ad libitum access to standard laboratory chow (Glen Forrest Stockfeeders, Glen Forrest, Australia) and water. All animal procedures were approved by the Animal Experimentation Ethics Committee of the University of Melbourne and complied with the Australian Code of Practice for the Care and Use of Animals for Scientific Purposes.

Rats were starved overnight and warmed under a heat lamp before receiving a single injection of $48 \mathrm{mg} / \mathrm{kg}$ streptozotocin (STZ) or citrate buffer vehicle $(0.1 \mathrm{~mol} / \mathrm{l}, \mathrm{pH} 4)$ into the tail vein. Rats were closely monitored and weighed daily, while food and water intake were measured weekly.

In vitro effects of low glucose on NPY overflow. Four weeks after STZ or vehicle treatment, rats were anaesthetised with pentobarbitone sodium (100 mg/kg i.p.; Nembutal, Merial Australia, Parramatta, Australia), a blood sample was obtained by cardiac puncture and rats were killed by decapitation. Plasma and urine glucose concentration was measured using an enzymatic method (Synchron CX-5 auto-analyser, Beckman Coulter Pty, Australia). Plasma glucose concentrations were higher than those previously reported due to the high dose of anaesthetic. Retroperitoneal white adipose tissue (Rp WAT), testicular WAT and liver were dissected and weighed. The brain was rapidly removed and the hypothalamus was dissected on ice by making two coronal cuts along the hypothalamic sulcis. The brain slice was turned onto its anterior surface then the hypothalamus was removed by making vertical incisions along the lateral edge of the hypothalamus. Two segments of hypothalamus were dissected; a dorsal segment containing the PVN and DMN, and a ventral segment containing the ARC and VMN. The dorsal medulla containing the NTS was also derived from a medullary section taken $1 \mathrm{~mm}$ rostral and $1 \mathrm{~mm}$ caudal to the borders of the area postrema. Tissue weights were consistent between treatment groups, with the dorsal hypothalamic segment weighing $38 \pm 2 \mathrm{mg}$, the ventral segment $44 \pm 3 \mathrm{mg}$ and the dorsal medulla $48 \pm 2 \mathrm{mg}$. Data are standardised for tissue mass. Tissues were sliced using a McIlwain tissue chopper (Mickle Laboratory Engineering, Guildford, UK), set at 400 microns, 
then transferred to individual cell culture wells (Nunc, Denmark; 24 multiwell plate) filled with $800 \mu$ modified Krebs solution containing $118 \mathrm{mmol} / \mathrm{l} \mathrm{NaCl}, 4.7 \mathrm{mmol} / \mathrm{l} \mathrm{KCl}$, $1.2 \mathrm{mmol} / 1 \mathrm{MgSO}_{4}, 1.2 \mathrm{mmol} / 1 \mathrm{KH}_{2} \mathrm{PO}_{4}, 25 \mathrm{mmol} / 1 \mathrm{NaHCO}_{3}$, $8 \mathrm{mmol} / \mathrm{l}$ glucose, $0.02 \mathrm{mmol} / \mathrm{l}$ bacitracin and $0.1 \%$ bovine serum albumin. The culture plate was placed in an orbital mixer incubator (Ratek; $55 \mathrm{rpm}, 37^{\circ} \mathrm{C}$ ) and was constantly gassed with carbogen $\left(95 \% \mathrm{O}_{2}: 5 \% \mathrm{CO}_{2}\right)$. After 90 min equilibration, during which the Krebs solution was replaced every $20 \mathrm{~min}$, samples were collected on ice. After two basal collections of $20 \mathrm{~min}$, tissues were exposed to Krebs containing $1.5 \mathrm{mmol} / \mathrm{l}$ glucose, followed by exposure to normal Krebs solution to assess recovery of NPY overflow. The low glucose concentration of $1.5 \mathrm{mmol} / \mathrm{l}$ was based on the glucose concentrations reported to elicit changes in nerve activity $[19,21]$; this is within the range of CNS concentrations experienced during hypoglycaemia. The tissues were challenged 40 min later with Krebs solution containing $45 \mathrm{mmol} / \mathrm{l} \mathrm{K} \mathrm{K}^{+}$(with reduced $\mathrm{Na}^{+}$to maintain osmolarity) to test the viability of the tissues. Each sample was centrifuged and the supernatant was stored at $-20^{\circ} \mathrm{C}$ for subsequent radioimmunoassay of NPY-like immunoreactivity (NPYLI) using an antibody raised in the rabbit and [125I]-NPY labelled with Bolton and Hunter reagent $(2000 \mathrm{Ci} / \mathrm{mmol}$, Amersham Australia) as described previously [27]. The detection limit of the assay is $2 \mathrm{pg} / \mathrm{tube}$.

In vivo effects of insulin on PVN NPY overflow. In vivo NPY overflow push-pull experiments were conducted as described previously [28] in male rats, 6 weeks after STZ $(n=10)$ or vehicle $(n=10)$ injection. Rats were urethane-anaesthetised (1.4 g/kg i.p.), ventilated and blood pressure and heart rate were monitored via a femoral artery catheter connected to a MacLab/4s data acquisition system (ADInstruments, Castle Hill, Australia). A push-pull probe (28 G inner "push" cannula, 22 G outer "pull" cannula, perfusion area approx. 0.5$1.0 \mathrm{~mm}^{2}$; Plastics One, Roanoke, Va., USA) was stereotaxically implanted just above the PVN of the hypothalamus (anterior $-1.6 \mathrm{~mm}$, lateral $0.6 \mathrm{~mm}$, ventral $-7.5 \mathrm{~mm}$; relative to bregma) so that the perfusion area covered mainly the right or left PVN. A modified physiological Ringer solution $(\mathrm{NaCl} 132, \mathrm{KCl} 3$, $\mathrm{CaCl}_{2}$ 1.3, $\mathrm{MgCl}_{2}$ 1.2, $\mathrm{NaH}_{2} \mathrm{PO}_{4}$ 0.3, $\mathrm{Na}_{2} \mathrm{HPO}_{4} 1.2 \mathrm{mmol} / \mathrm{l}$, and $0.15 \%$ BSA, $0.001 \%$ bacitracin) was perfused constantly through the probe at a rate of $14 \mu \mathrm{l} / \mathrm{min}$ by two peristaltic pumps (Ismatec, Zurich, Switzerland) with identical push and pull flow rates. Perfusate samples were collected on ice, into $10 \mu \mathrm{l} 0.1 \mathrm{~mol} / \mathrm{l} \mathrm{HCl}$, every $20 \mathrm{~min}$. All samples were immediately centrifuged at $12300 \mathrm{~g}$ for $30 \mathrm{~s}$, and the supernatant frozen at $-20^{\circ} \mathrm{C}$ for later lyophilisation and NPY assay. Data are shown as the sum of three 20 min collections (pg per $60 \mathrm{~min}$ ).

Following equilibration, basal perfusate samples were collected over 2 h. Neutral (soluble) insulin (Actrapid, Novo Nordisk, Sydney, Australia) was then given as a single intravenous bolus via a femoral vein catheter at a dose of 10 or $30 \mathrm{U} / \mathrm{kg}$ to control or diabetic rats respectively, in order to induce hypoglycaemia. Perfusate samples were then collected for the following $3 \mathrm{~h}$. Blood samples $(200 \mu \mathrm{l})$ were taken every hour for measurement of plasma glucose. At the end of the experiment rats were killed and the brain was removed and fixed in 10\% neutral buffered formalin to histologically verify probe placement.

Calculations and statistical analysis. Results are expressed as means \pm SEM. Differences in body, liver and WAT weight, food and water intake and glucose concentrations were analysed using Student's $t$ tests. In vitro and in vivo NPY overflow was analysed using ANOVA with repeated measures, followed by post hoc LSD tests. Probability values less than 0.05 $(p<0.05)$ were considered statistically significant.
Table 1 Physical and metabolic parameters in Sprague Dawley rats 4 weeks after injection with streptozotocin (STZ) or buffer (control)

\begin{tabular}{lcc}
\hline & $\begin{array}{l}\text { Control rats } \\
(n=8)\end{array}$ & $\begin{array}{l}\text { STZ rats } \\
(n=8)\end{array}$ \\
\hline Body weight $(\mathrm{g})$ & $395.6 \pm 15.8$ & $291.8 \pm 10.9^{\mathrm{a}}$ \\
24-h food intake $(\mathrm{g})$ & $32.2 \pm 0.7$ & $61.4 \pm 1.7^{\mathrm{a}}$ \\
24-h water intake $(\mathrm{g})$ & $38.3 \pm 2.7$ & $300.7 \pm 9.9^{\mathrm{a}}$ \\
Liver $(\mathrm{g})$ & $18.2 \pm 1.1$ & $14.4 \pm 0.7^{\mathrm{a}}$ \\
Test WAT $(\mathrm{g})$ & $5.1 \pm 0.7$ & $0.5 \pm 0.1^{\mathrm{a}}$ \\
Rp WAT $(\mathrm{g})$ & $4.3 \pm 0.4$ & $\mathrm{nd}$ \\
Plasma glucose $(\mathrm{mmol} / \mathrm{l})$ & $12.8 \pm 0.3$ & $40.9 \pm 1.3^{\mathrm{a}}$ \\
Urine glucose $(\mathrm{mmol} / \mathrm{l})$ & $0.7 \pm 0.1$ & $528.3 \pm 44.5^{\mathrm{a}}$ \\
\hline
\end{tabular}

a $p<0.01$ compared to control rats; nd not detected

Values presented are means \pm SEM

\section{Results}

In vitro NPY overflow in the dorsal hypothalamus. All rats began at similar weights $(186 \pm 1 \mathrm{~g})$. As shown in Table 1, 4 weeks after treatment the STZ-treated rats were lighter than the control rats $(p<0.01)$. They were also severely hyperglycaemic, hyperphagic and polydipsic. Food intake was increased by $91 \%$ in the diabetic rats, while their water intake was increased eightfold compared to control rats $(p<0.01)$. The decrease in body weight in diabetic rats was reflected by decrease in WAT mass $(p<0.01)$. The liver weight was also lower in the diabetic rats $(p<0.05)$. Plasma and urine glucose concentrations in the diabetic rats were increased by threefold and 750-fold respectively compared to control rats $(p<0.01)$.

Analysis of variance with repeated measures and LSD tests showed effects of treatment and time on NPY overflow in the dorsal hypothalamus (Fig. 1A). Treatment with STZ produced more than a threefold increase in basal NPY overflow compared to control rats $(p<0.05)$. Mean basal NPY overflow, calculated as the average of two basal collections prior to low glucose stimulus, were $1.6 \pm 0.2$ and $5.7 \pm 2.3 \mathrm{pg}$ . $20 \mathrm{~min}^{-1} \cdot \mathrm{mg}$ tissue ${ }^{-1}$, for control rats $(n=8)$ and diabetic rats $(n=7)$ respectively.

Figure 1A also illustrates the effect of low glucose on NPY overflow in the dorsal hypothalamus of both treatment groups. The low glucose stimulus elicited a reduction in NPY overflow in the diabetic animals $(p<0.05)$; NPY overflow then returned towards basal concentrations in the first post glucose collection. In control rats, no significant effect of reduced glucose was found on NPY overflow.

In vitro NPY overflow in the ventral hypothalamus. Streptozotocin-induced diabetes also induced an increase in basal NPY overflow in this region (Fig. 1B, $p<0.05$ ). Mean basal NPY overflow in the ventral hypothalamus of control rats $(n=8)$ and dia- 
A

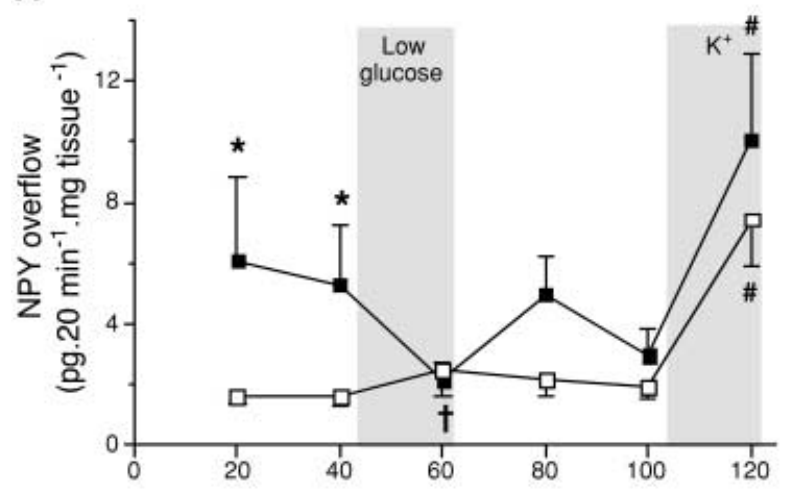

B

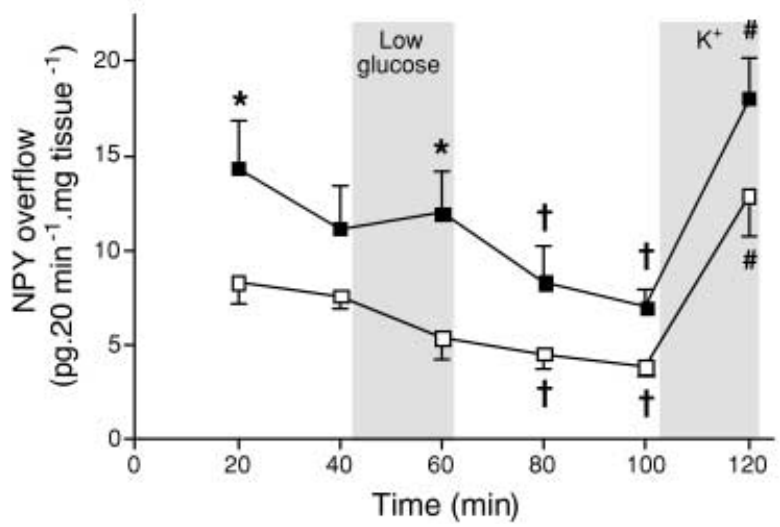

Fig. 1. Neuropeptide $Y$ overflow in the dorsal (A) and ventral (B) hypothalamus of diabetic rats (closed squares, $n=7-8$ ) and control rats (open squares, $n=8$ ), expressed as $\mathrm{pg} \cdot 20 \mathrm{~min}^{-1} \cdot \mathrm{mg}$ tissue $^{-1}$. Tissues were exposed to low glucose Krebs buffer $\left(1.5 \mathrm{mmol} / \mathrm{l}\right.$ glucose) and high $\mathrm{K}^{+} \mathrm{Krebs}$ buffer $\left(45 \mathrm{mmol} / \mathrm{l} \mathrm{K}{ }^{+}\right)$ during the periods indicated. * $p<0.05$ compared to control rats; $\dagger p<0.05$ compared to first collection; \#p<0.05 compared to pre-high $\mathrm{K}^{+}$collection

betic rats $(n=8)$ was $8.3 \pm 1.1$ and $14.4 \pm 2.4 \mathrm{pg}$. $20 \mathrm{~min}^{-1} \cdot \mathrm{mg}$ tissue ${ }^{-1}$, respectively. There was no significant effect of exposure to low glucose evident in the ventral hypothalamus of either group (Fig. 1B). In this tissue, there seemed to be some decline in basal NPY overflow over time. Higher amounts of NPY were found in the ventral compared to dorsal hypothalamus in both the control group and diabetic group $(p<0.05)$.

In vitro NPY overflow in the dorsal medulla. Neuropeptide Y overflow in the dorsal medulla of control and diabetic rats is illustrated in Fig. 2. No difference was observed in basal NPY overflow between control rats and diabetic rats $(1.4 \pm 0.3$ and $1.6 \pm 0.2 \mathrm{pg}$. $20 \mathrm{~min}^{-1} \cdot \mathrm{mg} \mathrm{tissue}^{-1}$ respectively; $n=5,6$ ), indicating no significant effect of STZ treatment on NPY overflow in the dorsal medulla. Low glucose stimulus did not cause any change in NPY overflow in either treatment group (Fig. 2).

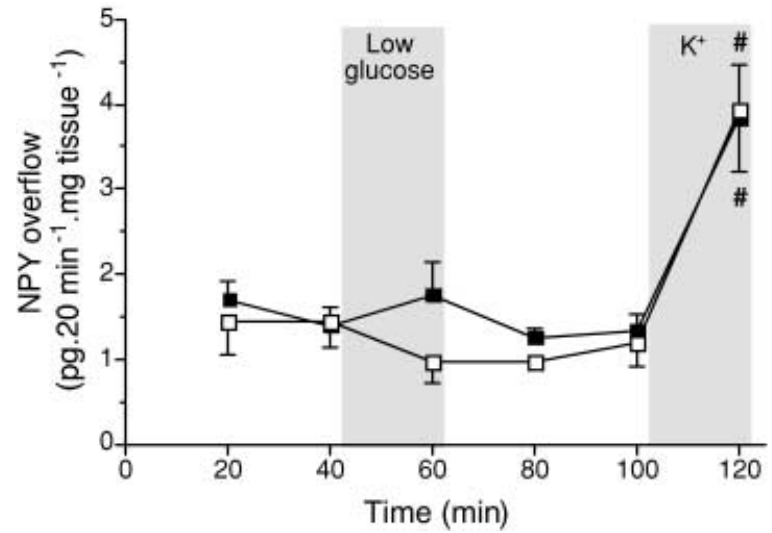

Fig. 2. Neuropeptide Y overflow in the dorsal medulla of diabetic rats (closed squares, $n=6$ ) and control rats (open squares, $n=5)$, expressed as $\mathrm{pg} \cdot 20 \mathrm{~min}^{-1} \cdot \mathrm{mg}$ tissue ${ }^{-1}$. Tissues were exposed to low glucose Krebs buffer $(1.5 \mathrm{mmol} / \mathrm{l}$ glucose) and high $\mathrm{K}^{+}$Krebs buffer $\left(45 \mathrm{mmol} / \mathrm{l} \mathrm{K}^{+}\right)$during the periods indicated. $\# p<0.05$ compared to pre-high $\mathrm{K}^{+}$collection

Effects of KCI stimulus on in vitro PNY overflow. Potassium depolarisation-induced increases in NPY overflow were observed in all brain regions examined, with a similar threefold increase in diabetic rats and control rats $(p<0.01$; Figs. 1,2$)$.

In vivo NPY overflow in the hypothalamic PVN. Rats used in the in vivo study showed similar physical and metabolic parameters to those used in the in vitro study. Basal plasma glucose concentrations in the fed state were more than tripled in the diabetic rats compared to control rats $(29.8 \pm 2.1$ and $9.8 \pm 0.7 \mathrm{mmol} / \mathrm{l} \mathrm{re}-$ spectively, $n=10,10, p<0.05$, Fig. 3B). An intravenous insulin bolus produced a rapid fall in plasma glucose concentrations in all rats, with control rats reaching hypoglycaemic concentrations $(<2.5 \mathrm{mmol} / \mathrm{l})$ by 60 min after insulin administration (Fig. 3B). Plasma glucose concentration in diabetic rats reached $8.1 \pm 1.2 \mathrm{mmol} / \mathrm{l}$ by the end of the experiment, and was not different from control rats at this time point (Fig. 3B). This reduction of $73.3 \%$ in glucose from basal concentrations in the diabetic rats was similar to the $76.8 \%$ reduction achieved in the control rats.

Basal NPY overflow from the PVN was doubled in the STZ-treated diabetic rats compared to control rats (77.1 \pm 15.4 and $38.2 \pm 5.2 \mathrm{pg} \cdot 60 \mathrm{~min}^{-1}$ respectively; $n=10,10, p<0.05$, Fig. 3A). Insulin-induced hypoglycaemia produced an increase in PVN NPY overflow in the control rats by $2 \mathrm{~h}(p<0.05)$ reaching $157 \%$ of basal concentrations by 3 -h post insulin. In contrast, diabetic rats showed a reduction in PVN NPY overflow after insulin, which became significant at 3 -h post insulin, reaching $65 \%$ of basal concentrations $(p<0.05$, Fig. 3A). The changes in NPY overflow and plasma glucose concentrations seemed to follow similar time courses in both groups of rats (Fig. 3A,B). PVN NPY overflow remained constant in both diabet- 
A
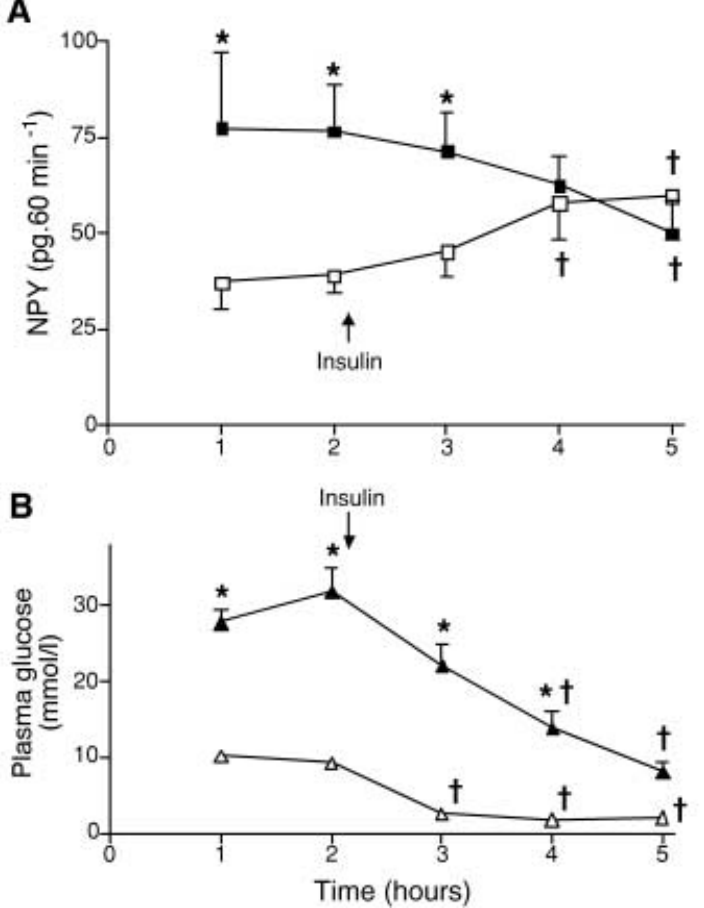

Fig. 3. Hypothalamic PVN neuropeptide $Y$ overflow, expressed as pg measured in the preceding $60 \mathrm{~min},(\mathbf{A})$ and plasma glucose, expressed as $\mathrm{mmol} / \mathrm{l},(\mathbf{B})$ in diabetic rats (closed symbols, $n=10$ ) and control rats (open symbols, $n=10$ ). An intravenous insulin bolus of $30 \mathrm{U} / \mathrm{kg}$ (diabetic rats) or $10 \mathrm{U} / \mathrm{kg}$ (control rats) was administered where indicated by an arrow. $* p<0.05$ compared to control rats; $\dagger p<0.05$ compared to both basal samples

ic rats and control rats in time control experiments $(n=2)$ where no insulin infusion was given.

\section{Discussion}

The majority of GS neurons in the ARC were recently shown to contain NPY [19], suggesting a role for NPY in glucose sensing. Under conditions of negative energy balance, such as untreated Type I diabetes, the arcuo-PVN NPY-containing pathway seems to be stimulated, resulting in increased peptide and $N P Y$ mRNA, which is thought to be associated with hyperphagia in these animals $[25,26,29]$. The increased NPY content in STZ-treated rats was largely associated with the ARC and PVN [26].

In this study, we investigated the dorsal and ventral segments of the hypothalamus, aiming to separately examine the PVN and ARC. The PVN is known to contain GR neurons, while the ARC contains both GS [19] and GR [30] neurons. The ventral hypothalamus segment also incorporated the VMN, which contains both GR, and somewhat fewer, GS neurons [15]. In line with previous studies [26] increased basal NPY overflow was observed in both the dorsal and ventral hypothalamus as a result of treatment with STZ, and the increase was greater in the dorsal area. Consistent with preliminary studies in our laboratory, higher NPY overflow was observed in the ventral compared to dorsal hypothalamus. While NPY terminals are abundant in the PVN, NPY perikarya are localised in the ARC [23]. Moreover, the ventral hypothalamus segment we examined also contained the VMN and part of the LH, possibly contributing to the higher NPY overflow from this region.

Dorsal hypothalamus. The in vitro study showed a selective reduction in NPY overflow in response to a low glucose stimulus in the dorsal hypothalamus of diabetic rats. The tissues recovered from the low glucose stimulus, as the NPY overflow returned towards basal concentrations in the next collection. The dorsal segment of the hypothalamus contained the PVN and DMN. Although there is little evidence to date regarding the role of the DMN in glucose sensing, the importance of the PVN in glucose sensing has been well established. In addition to studies showing activation of neurons in the PVN during hypoglycaemia [31], another study [32] also reported suppression of PVN activation after antecedent hypoglycaemia, suggesting its importance in the development of hypoglycaemia unawareness. A decreased glucose concentration could conceivably decrease activation of GR neurons in the PVN, and consequently reduce the release of transmitters. The reduced NPY overflow in response to low glucose concentrations in the dorsal hypothalamus supports some involvement of NPY in glucose sensing, at least in Type I diabetes. However, we cannot discount the possibility that the alteration in NPY overflow occurs secondary to changes in another transmitter [13]. This reduced release was only observed in the diabetic rats and suggests an increased response of the diabetic rats to lowered glucose concentrations.

These in vitro findings prompted us to examine NPY overflow in vivo, using push-pull techniques that allow release from a discrete terminal area to be measured in an intact animal. Results of these experiments supported the in vitro findings, as diabetic rats had increased NPY overflow from the PVN at rest, and responded to a lowering of blood glucose by reducing NPY overflow. NPY overflow was somewhat increased in control rats after hypoglycaemia, suggesting an altered responsiveness in diabetic rats that could involve NPY. The diabetic rats in our study were untreated and had extremely high plasma glucose concentrations. It has been reported [33] that neither blood-to-brain glucose transport nor cerebral glucose metabolism are reduced in poorly controlled Type I diabetic patients, which is in agreement with animal studies [34]. Thus the diabetic animals would have manifested higher brain glucose. Although the diabetic rats did not achieve the same absolute concentration of glucose as the control rats, the magnitude of the reduction was similar when compared to 
resting glucose concentrations. Moreover, clinical studies show that hypoglycaemia could be perceived at higher plasma glucose concentrations in diabetic patients. Early neuroglycopenic symptoms in poorly controlled Type I diabetic patients occurred at a plasma glucose concentration of $4.4 \mathrm{mmol} / \mathrm{l}$ as compared with 2.8 to $3.1 \mathrm{mmol} / \mathrm{l}$ in healthy subjects [7].

Ventral hypothalamus. The ARC contains the cell bodies of NPY-ergic neurons projecting to other hypothalamic regions, and receives some innervation from NPY-ergic neurons in the brainstem [23, 35]. Neuropeptide $\mathrm{Y}$ immunoreactivity in this region has been linked to both GS [19] and GR [30] functions. The ventral hypothalamus segment also incorporated the VMN, a predominantly GR area that receives NPY containing projections from the ARC. Thus lowering of brain glucose could cause an increase in GS neuron firing, resulting in increased release of NPY, but this would be balanced by a reduction in GR cell firing. This could underlie our observation in vitro, of no significant difference in NPY overflow in either diabetic rats or control rats when glucose was lowered. There is extensive evidence on the importance of the VMN in glucose homeostasis. As well as being one of the areas with the highest density of GR neurons, impairing the function of the VMN $\mathrm{K}_{\text {ATP }}$ channels in Kir 6.2mice was shown to produce a major defect in glucagon secretion in response to hypoglycaemia [36]. The presence of neurons with opposing glucose sensing actions could have made it difficult to observe an effect of lowered glucose in vitro.

Medulla. Glucose sensing structures have also been reported in the caudal part of the NTS in the medulla [22], where $\mathrm{K}_{\text {ATP }}$ channels have been pharmacologically identified [37]. Our data showed no significant effect of low glucose on NPY overflow in the dorsal medulla in both control rats and diabetic rats. A mixed population of GR and GS neurons in the rat dorsal medulla could explain this observation. Within the NTS, some neurons are activated by glucose, some depressed, while others show no response to altered glucose concentrations [37]. While most regulation of feeding and glucose homeostasis takes place in the hypothalamus, the NTS seems to act as a relay point where information regarding glucose status received from the periphery is integrated and projected either caudally or rostrally to the hypothalamus [13]. In our in vitro study, this integration of central and peripheral information was disrupted. It is therefore difficult to determine the importance of local glucose concentrations in this region since glucose sensing in the dorsal medulla could rely greatly on peripheral signals. Contrary to our result in the hypothalamus, treatment with STZ did not alter basal NPY overflow in the dorsal medulla.

Glucose sensors in the hypothalamus most likely act in synergy with hormonal signals, as in pancreatic beta cells [38]. Glucose-responsive cells could be sensitive to leptin, the obese gene product secreted by adipocytes that regulates appetite. Neuropeptide $\mathrm{Y}$ is strongly regulated by leptin, and we have shown acute inhibitory effects of leptin on hypothalamic NPY overflow [39]. Previous work in our laboratory has shown large reductions in plasma leptin concentrations in diabetic rats, to around $3 \%$ of vehicle treated controls, in keeping with the $90 \%$ reduction in adipose tissue stores we observed. Neuropeptide Y is also subject to regulation by insulin, as well as leptin, and it is likely the reduction in insulin after STZ contributed to the increased basal NPY overflow seen in diabetic rats. Direct inhibitory effects of insulin on NPY overflow were reported in food deprived rats [40] and intracerebroventricular administration of insulin was shown to inhibit NPY gene expression [41]. More work is required to establish whether leptin, in addition to insulin, contributes to the physiological responses to altered glucose status. In our study the effects we observed on in vivo NPY overflow could be ascribed to hypoglycaemia per se, or in part, to a direct effect of insulin on NPY overflow, and further work is required to establish the relative contributions. However, the similarity of the in vivo and in vitro responses to lowered glucose suggests low glucose is an important signal regulating NPY overflow.

Release of NPY can be evoked by activating voltage-dependent $\mathrm{Ca}^{+}$channels that are sensitive to depolarisation. Our study showed that regardless of treatment, both dorsal and ventral hypothalamic and dorsal medullary tissues responded to $\mathrm{K}^{+}$-induced depolarisation with a threefold increase in NPY overflow. This indicates the viability of the tissues and confirms the validity of the in vitro system in detecting changes in NPY overflow in response to different stimuli. Previous work from our laboratory and others indicate similar increases in PVN NPY overflow occur in vivo in response to $\mathrm{K}^{+}$-induced depolarisation $[28,42]$.

We observed a region-specific reduction in NPY overflow in response to a low glucose stimulus in the dorsal hypothalamus (in vitro) and PVN (in vivo) of diabetic rats. The effect of low glucose in vivo could indicate altered activity of NPY-containing projections to the PVN, which could arise in the ARC and DMN or ascending projections from the medullary catecholamine cells. It should also be noted that only a small proportion of neurons would likely contribute to any changes induced by alterations in glucose, as glucose sensing neurons comprise a subset of the neuron population [43]. Overall our data suggest cells in the dorsal hypothalamus could be more sensitive to lowered glucose in diabetes. It is difficult to say what the physiological importance of the reduced NPY overflow in response to low glucose might be. However, changes in NPY in the PVN are critically involved in feeding status. A reduction in NPY in the face of hypoglycae- 
mia in the diabetic rat would normally reduce food intake, whereas the opposite response we observed in vivo in control rats, would stimulate feeding, and presumably return glucose towards normal concentrations. Recent studies suggest an important link between glucose sensing and another orexigenic peptide, orexin [44]. Responses of glucose sensing neurons to altered glucose status is likely to have relevance to obesity in addition to diabetes $[15,45]$, particularly as we have shown a $61 \%$ reduction in NPY content in the PVN of rats made obese by chronic high fat feeding [46].

In conclusion, the dysregulation of glucose sensing in Type I diabetes seems to involve a major resetting of the brain's normal ability to respond to changes in glucose. Glucose is known to affect the activity of glucose sensing neurons, which in turn could affect the release of transmitters. Understanding the part of the mediators involved in this process would improve our understanding of how the brain senses glucose. Our data indicate an altered NPY response to lowered glucose in diabetes, particularly in the PVN. Therefore our study provides further evidence for the involvement of NPY in brain glucose sensing, particularly during hypoglycaemic challenge. It also provides evidence showing that this response is altered in Type I diabetes.

Acknowledgements. This study was supported by a grant from the Juvenile Diabetes Research Foundation. We are thankful to A. Gibson for glucose measurements and Prof. B. Jarrott for the gift of NPY antibody.

\section{References}

1. Brinchmann-Hansen O, Dahl-Jorgensen K, Sandvik L, Hanssen KF (1992) Blood glucose concentrations and progression of diabetic retinopathy: the seven year results of the Oslo study. BMJ 304: 19-22

2. Diabetes Control and Complications Trial Research Group (1993) The effect of intensive treatment of diabetes on the development and progression of long-term complications in insulin-dependent diabetes mellitus. N Engl J Med 329: 977-986

3. Herbel G, Boyle PJ (2000) Hypoglycemia. Pathophysiology and treatment. Endocrinol Metab Clin North Am 29: 725-743

4. Strachan MW, Deary IJ, Ewing FM, Ferguson SS, Young MJ, Frier BM (2001) Acute hypoglycemia impairs the functioning of the central but not peripheral nervous system. Physiol Behav 72: 83-92

5. Gerich JE (1988) Glucose counterregulation and its impact on diabetes mellitus. Diabetes 37: 1608-1617

6. Cryer PE (1999) Symptoms of hypoglycemia, thresholds for their occurrence, and hypoglycemia unawareness. Endocrinol Metab Clin North Am 28: 495-500

7. Boyle PJ, Schwartz NS, Shah SD, Clutter WE, Cryer PE (1988) Plasma glucose concentrations at the onset of hypoglycemic symptoms in patients with poorly controlled diabetes and in nondiabetics. N Engl J Med 318: 14871492
8. Amiel SA, Sherwin RS, Simonson DC, Tamborlane WV (1988) Effect of intensive insulin therapy on glycemic thresholds for counterregulatory hormone release. Diabetes 37: 901-907

9. White NH, Skor DA, Cryer PE (1983) Identification of type 1 diabetic patients at increased risk for hypoglycemia during intensive therapy. N Engl J Med 308: 485

10. Hepburn DA, Patrick AW, Eadington DW, Ewing DJ, Frier BM (1990) Unawareness of hypoglycemia in insulin-treated diabetic patients: prevalence and relationship to autonomic neuropathy. Diabet Med 7: 711-717

11. Boyle PJ, Kempers SF, O'Connor AM, Nagy RJ (1995) Brain glucose and uptake and unawareness of hypoglycemia in patients with insulin-dependent diabetes mellitus. N Engl J Med 333: 1726-1731

12. Korytkowski MT, Mokan M, Veneman TF, Mitrakou A, Cryer PE, Gerich JE (1998) Reduced beta-adrenergic sensitivity in patients with type 1 diabetes and hypoglycemia unawareness. Diabetes Care 21: 1939-1943

13. Oomura Y (1983) Glucose as a regulator of neuronal activity. Adv Metab Disord 10: 31-65

14. Dagogo-Jack S, Rattarasarn C, Cryer PE (1994) Reversal of hypoglycemia unawareness, but not defective glucose counterregulation, in IDDM. Diabetes 43: 1426-1434

15. Song Z, Levin BE, McArdle JJ, Bakhos N, Routh VH (2001) Convergence of pre-and postsynaptic influences on glucosensing neurons in the ventromedial hypothalamic nucleus. Diabetes 50: 2673-2681

16. Mayer J (1955) Regulation of energy intake and the body weight: the glucostatic theory and lipostatic hypothesis. Ann NY Acad Sci 63: 15-43

17. Oomura Y, Kimura K, Ooyama T, Maeo M, Iki M, Kuniyoshi N (1964) Reciprocal activities of the ventromedial and lateral hypothalamic area of cats. Science 143: 484-485

18. Kow LM, Pfaff DW (1989) Responses of hypothalamic paraventricular neurons in vitro to norepinephrine and other feeding-relevant agents. Physiol Behav 46: 265-271

19. Muroya S, Yada T, Shioda S, Takigawa M (1999) Glucosesensitive neurons in the rat arcuate nucleus contain neuropeptide Y. Neurosci Lett 264: 113-116

20. Yettefti K, Orsini JC, Perrin J (1997) Characteristics of glycemia-sensitive neurons in the nucleus tractus solitarii: possible involvement in nutritional regulation. Physiol Behav 61: 93-100

21. Dallaporta M, Himmi T, Perrin J, Orsini JC (1999) Solitary tract nucleus sensitivity to moderate changes in glucose level. Neuroreport 10: 2657-2660

22. Sanders NM, Ritter S (2000) Repeated 2-deoxy-D-glucoseinduced glucoprivation attenuates fos expression and glucoregulatory responses during subsequent glucoprivation. Diabetes 49: 1865-1874

23. Bai FL, Yamano M, Shiotani Y et al. (1985) An arcuatoparaventricular and -dorsomedial hypothalamic neuropeptide Y-containing system which lacks noradrenaline in the rat. Brain Res 331: 172-175

24. Stanley BG, Kyrkouli SE, Lampert S, Liebowitz SF (1986) Neuropeptide Y chronically injected into the hypothalamus: a powerful neurochemical inducer of hyperphagia. Peptides 7: 1189-1192

25. White JD, Olchovsky D, Kershaw M, Berelowitz M (1990) Increased hypothalamic content of preproneuropeptide-Y messenger ribonucleic acid in streptozotocin-diabetic rats. Endocrinology 126: 765-772

26. Sahu A, Sninsky CA, Phelps CP, Dube MG, Kalra PS, Kalra SP (1992) Neuropeptide Y release from the paraventricular nucleus increases in association with hyperphagia 
in streptozotocin-induced diabetic rats. Endocrinology 131: 2979-2985

27. Morris MJ, Russell AE, Kapoor V et al. (1986) Increases in plasma neuropeptide $\mathrm{Y}$ concentrations during sympathetic activation in man. J Auton Nerv Syst 17: 143-149

28. Morris MJ, Hastings JA, Pavia JM (1997) Central interactions between noradrenaline and neuropeptide $\mathrm{Y}$ in the rat: implications for blood pressure control. Clin Exp Hypertens 19: 619-630

29. Williams G, Gill JS, Lee YC, Cardoso HM, Okpere BE, Bloom SR (1989) Increased neuropeptide Y concentrations in the specific hypothalamic regions of the streptozotocin induced diabetic rat. Diabetes 38: 321-327

30. Dunn-Meynell AA, Rawson NE, Levin BE (1998) Distribution and phenotype of neurons containing the ATP-sensitive $\mathrm{K}^{+}$channel in rat brain. Brain Res 814: 41-54

31. Beverly JL, De Vries MG, Bouman SD, Arseneau LM (2001) Noradrenergic and GABAergic systems in the medial hypothalamus are activated during hypoglycemia. Am J Physiol 280: R563-R569

32. Evans SB, Wilkinson CW, Bentson K, Gronbeck P, Zavosh A, Figlewicz DP (2001) PVN activation is suppressed by repeated hypoglycemia but not antecedent corticosterone in the rat. Am J Physiol 281: R1426-R1436

33. Fanelli CG, Dence CS, Markham J et al. (1998) Bloodtobrain glucose transport and cerebral glucose metabolism are not reduced in poorly controlled type 1 diabetes. Diabetes 47: $1444-1450$

34. Simpson IA, Appel NM, Hokari M et al. (1999) Bloodbrain barrier glucose transporter: effects of hypo- and hyperglycemia revisited. J Neurochem 72: 238-247

35. Sahu A, Kalra SP, Crowley WR, Kalra PS (1988) Evidence that NPY-containing neurons in the brainstem project into selected hypothalamic nuclei: implication in feeding behavior. Brain Res 457: 376-378

36. Miki T, Liss B, Minami K et al. (2001) ATP-sensitive $\mathrm{K}^{+}$ channels in the hypothalamus are essential for the maintenance of glucose homeostasis. Nat Neurosci 4: 507-512
37. Dallaporta M, Perrin J, Orsini J-C (2000) Involvement of adenosine triphosphate-sensitive $\mathrm{K}^{+}$channels in glucosesensing in the rat solitary tract nucleus. Neurosci Lett 278: $77-80$

38. Schuit FC, Huypens P, Heimberg H, Pipeleers DG (2001) Glucose sensing in pancreatic beta cells; a model for other glucose regulated cells in gut, pancreas and hypothalamus. Diabetes 50: 1-11

39. Lee J, Morris MJ (1998) Modulation of neuropeptide Y overflow by leptin in the rat hypothalamus, cerebral cortex and medulla. Neuroreport 9: 1575-1580

40. Sahu A, Dube MG, Phelps CP, Sninsky CA, Kalra PS, Kalra SP (1995) Insulin and insulin-like growth factor II suppress neuropeptide $\mathrm{Y}$ release from the nerve terminals in the paraventricular nucleus: a putative hypothalamic site for energy homeostasis. Endocrinology 136: 5718-5724

41. Wang J, Leibowitz KL (1997) Central insulin inhibits hypothalamic galanin and neuropeptide $\mathrm{Y}$ gene expression and peptide release in intact rats. Brain Res 777: 231-236

42. Stricker-Krongrad A, Barbanel G, Beck B, Burlet A, Nicolas JP, Burlet C (1993) $\mathrm{K}^{+}$-stimulated neuropeptide Y release into the paraventricular nucleus and relation to feeding behavior in free-moving rats. Neuropeptides 24: 307-312

43. Silver IA, Erecinska M (1998) Glucose-induced intracellular ion changes in sugar-sensitive hypothalamic neurons. J Neurophysiol 79: 1733-1745

44. Liu XH, Morris R, Spiller D, White M, Williams G (2001) Orexin a preferentially excites glucose-sensitive neurons in the lateral hypothalamus of the rat in vitro. Diabetes 50: 2431-2437

45. Levin BE, Dunn-Meynell AA, Routh VH (1999) Brain glucose sensing and body energy homeostasis: role in obesity and diabetes. Am J Physiol 276: R1223-R1231

46. Hansen MJ, Ball MJ, Morris MJ (2001) Enhanced inhibitory feeding response to alpha-melanocyte stimulating hormone in the diet-induced obese rat. Brain Res 892: 130137 